\title{
EL XVIII Congreso de la Sociedad Española de Educación Médica
}

Durante los días 24 a 26 de octubre de 2007 se ha celebrado en Santa Cruz de Tenerife, organizado conjuntamente por las Facultades de Medicina de las Universidades de la Laguna y de Las Palmas de Gran Canarias, el XVIII Congreso de la Sociedad Española de Educación Médica.

El congreso se inició con un acto presidido por los Rectores de las dos Universidades Canarias en la que se otorgó el II Premio Antonio Gallego, a la Excelencia de una Carrera Educación Médica al Prof. José María Segovia de Arana, impulsor del sistema de formación de especialistas en España. La figura del premiado fue glosada por el Prof. Antonio Alarcó, Presidente del Comité Organizador local. Posteriormente se hizo entrega de sendas placas conmemorativas a la Profa. M. Barón Maldonado, ex - presidenta de SEDEM y de AMEE y al Prof. PazBouza, ex - presidente de la Conferencia Nacional de Decanos de Facultades de Medicina españolas. Finalmente la Profa. Madalena de la Universidad de Lisboa, y Presidenta de AMEE, pronunció la conferencia inaugural The Bologna Process: State of the Art after the 2007 London Ministerial Conference.

Durante el congreso se celebraron 9 sesiones de comunicaciones orales ascendiendo a un total de 93 comunicaciones y 4 sesiones de comunicaciones en forma de panel con 40 presentaciones, lo que hace un total de 133 comunicaciones. Este número supone un incremento del $12 \%$ en relación a la anterior edición del congreso. El 65\% de las comunicaciones correspondieron al área del pregrado y el 35\% al área del postgrado. Dentro de estas dos grandes áreas, los temas de las diferentes sesiones fueron dedicadas a la formación orientada en competencias, la enseñanza clínica y su evaluación, la adaptación de planes de estudio al Espacio Europeo de Educación Superior, las metodologías docentes, la evaluación, la calidad en la formación de postgrado, la función de los tutores de postgrado y las nuevas tecnologías. Se apreció en la mayoría de las comunicaciones un importante incremento de su calidad.

El congreso celebraron dos mesas redondas sobre el tema ¿Faltan Médicos?. ¿Cuestión cuantitativa o cualitativa?, y La responsabilidad del Continuum en Educación Médica en el contexto del Espacio Europeo de Educación Superior, con la participación de dos paneles de expertos correspondientes a las diferentes instancias implicadas. Las conclusiones de las dos mesas redondas se detallan al final de este resumen. Se desarrolló también el Forum Miriam Friedman dedicado al uso de simulaciones en Educación Médica con la participación de dos expertos, uno nacional el Prof. G. Vázquez de Granada y otro internacional, el Prof. Amitai Ziv de Israel. Finalmente se celebraron 3 sesiones temáticas dedicadas a los siguientes temas: a) ¿Cómo incorporar la adquisición de competencias en el plan de estudios?; b) La enseñanza de la Fisiología en el contexto del Espacio Europeo de Educación superior y c) Medicina Familiar y Universidad: Papel de las Unidades Docentes de MFyC. Por último se presentó el proyecto impulsado por AMEE y en el cual colabora la SEDEM sobre el establecimiento de una base de datos sobre Educación Médica, denominada MedEdCentral.

Así mismo se celebraron 3 talleres, uno sobre Evaluación de competencias, otro sobre Portafolio docente y un tercero sobre Aprendizaje basado en problemas.

El total de inscritos alcanzó los 250 participantes, procedentes de todas las comunidades autónomas y de todos los campos de la educación médica (pregrado, postgrado y formación continuada). Hemos de destacar también la presencia de congresistas procedentes de Portugal y de varios países de Latinoamérica como Argentina, Chile. Méjico y Venezuela y de Asia como Ubekistán.

La SEDEM y su junta directiva se felicita por el éxito del XVIII Congreso y quiere agradecer a todos los inscritos su participación y su colaboración. Así mismo desea expresar su reconocimiento y agradecimiento a las Universidad de La Laguna y de Las Palmas de Gran Canaria, al Comité Organizador, al Gobierno de Canarias, al Cabildo de Tenerife, Ayuntamiento de Santa Cruz de Tenerife y Conferencia Nacional de Decanos de Medicina por $\mathrm{su}$ apoyo institucional y económico y a diversas empresas privadas por sus aportaciones.

Finalmente la Sociedad Española de Educación Médica convoca a todos los educadores médicos a asistir al XIX Congreso de la SEDEM que se celebrará el mes de septiembre de 2009 en Málaga conjuntamente con la Conferencia Anual de la International Association for Medical Education (AMEE). Todos ellos a través de www.sedem.org y de la AMEE (www.amee.org) y del correo electrónico recibirán en su momento toda la información. 


\section{CONCLUSIONES DE LAS PONENCIAS DEL XVIII CONGRESO}

Mesa 1

\section{¿Faltan médicos? ¿Cuestión cuantitativa o cualitativa?}

El número de médicos depende del sistema de salud que nos dotemos.

La administración debe reformar el sistema sanitario para hacerlo más flexible, eficiente, atractivo y adecuado al ejercicio profesional.

No es necesario incrementar el número de estudiantes de medicina.

Algunas especialidades médicas son deficitarias en cuanto al número de profesionales.

Es preciso aprovechar el potencial docente de las unidades asistenciales.

Hay que corregir algunos aspectos relacionados con la prueba de acceso a la formación especializada y en el proceso de adjudicación de plazas.

Es necesario incentivar a nuestros médicos para que permanezcan en nuestro país.

\section{Mesa II}

La responsabilidad del continuum educativo en el contexto del EEES

La formación de los médicos tiene un fin social por lo que debe ser "tutelada" por todos los agentes implicados: $i$ ) ciudadanos/pacientes, ii) Administraciones educativa/sanitaria, iii) Organizaciones profesionales colegios/sociedades científicas, y iv) empleadores.

La formación de Grado es la vía natural de entrada a la formación especializada de modo que sus contenidos y metodologías deben facilitar al máximo el aprendizaje de Postgrado, optimizando recursos y tiempo.

Para la sintonización entre el Grado y el Postgrado es necesario una estructura estable, con capacidad ejecutiva, en la que converjan tanto los responsables de las administraciones educativa y sanitaria como los responsables de la formación, Facultades de Medicina y Unidades Docentes, y en la que además deben participar el resto de los actores implicados. 